\title{
Spuriously Normal Amylase Levels in a Patient With Acute Pancreatitis Secondary to Hypertriglyceridemia
}

\author{
Kristen Okerberg, $M D$, and Makau Lee, $M D, P b D$
}

Acute pancreatitis is a disease that has varied clinical manifestations often requiring clinicians to rely on laboratory tests, such as serum amylase and lipase, as diagnostic aids. 1,2 Patients with acute pancreatitis, however, can have normal amylase levels as a result of hypertriglyceridemia. ${ }^{3}$ The aims of this report are to describe a case of acute pancreatitis secondary to hypertriglyceridemia, to discuss the diagnostic dilemma caused by lactescent plasma, and to review the therapeutic options for this type of pancreatitis.

\section{Case Report}

A 41-year-old woman was admitted for evaluation of severe abdominal pain of 1 day's duration accompanied by nausea, vomiting, and subjective fever. Her medical history was notable for diabetes mellitus and hypercholesterolemia. The patient was a nonsmoker, and she denied any alcohol consumption. Her only medication at admission was subcutaneous insulin for her diabetes.

At admission, the patient's temperature was $100^{\circ} \mathrm{F}$, respiratory rate $18 / \mathrm{min}$, pulse 89 beats per minute and blood pressure $124 / 70 \mathrm{mmHg}$. She had diffuse abdominal tenderness without guarding or rebound tenderness, hypoactive bowel sounds, and no hepatosplenomegaly. Rectally there were no masses, and stool was guaiac negative. Findings on the remainder of the physical examination were unremarkable. Laboratory values included a peripheral white blood cell count $10.8 \times$ $10^{3} / \mathrm{mL}$ (with a normal differential count), hemoglobin $12.9 \mathrm{~g} / \mathrm{dL}$, hematocrit 39 percent, and platelets $239,000 / \mathrm{mL}$. Serum electrolytes were within normal limits with a blood urea nitrogen of $1.0 \mathrm{mg} / \mathrm{dL}$, creatinine of $0.4 \mathrm{mg} / \mathrm{dL}$, and calcium of $8.3 \mathrm{mg} / \mathrm{dL}$ (normal, $8.7-10.6 \mathrm{mg} / \mathrm{dL}$ ). Liver

Submitted 26 January 1998.

From the Department of Medicine (KO, ML), University of Texas Health Science Center, San Antonio. Address reprint requests to Makau Lee, MD, PhD, Division of Digestive Diseases/Medicine, University of Mississippi Medical Center, 2500 North State St, Jackson, MS 39216-4504 function tests included total bilirubin $1.3 \mathrm{mg} / \mathrm{dL}$ (normal, $0.2-1.2 \mathrm{mg} / \mathrm{dL}$ ), aspartate aminotransferase $25 \mathrm{IU} / \mathrm{L}$ (normal, 8 - $42 \mathrm{IU} / \mathrm{L}$ ), alanine aminotransferase $18 \mathrm{IU} / \mathrm{L}$ (normal, 3 - $36 \mathrm{IU} / \mathrm{L}$ ), and alkaline phosphatase $60 \mathrm{IU} / \mathrm{L}$ (normal, 50 $125 \mathrm{IU} / \mathrm{L})$. Other pertinent laboratory values included a serum amylase of $74 \mathrm{IU} / \mathrm{L}$ (normal, 40 $125 \mathrm{IU} / \mathrm{L}$ ), serum lipase of $106 \mathrm{IU} / \mathrm{L}$ (normal, 4 $24 \mathrm{IU} / \mathrm{L}$ ), triglycerides of $9990 \mathrm{mg} / \mathrm{dL}$ (normal, 10- $249 \mathrm{mg} / \mathrm{dL})$, and a cholesterol level of 1255 $\mathrm{mg} / \mathrm{dL}$ (normal, 150 - $199 \mathrm{mg} / \mathrm{dL}$ ).

A diagnosis of acute pancreatitis was made. The patient was treated with nothing by mouth, nasogastric suction, pain control with meperidine, antiemetic therapy with promethazine, intravenous insulin infusion, and parenteral hyperalimentation. On hospital day 2, a sonogram showed no evidence of gallbladder disease or dilatation of bile ducts. Abdominal computed tomography (CT) showed inflammatory changes surrounding the pancreas consistent with acute pancreatitis and a fatty liver. The patient's condition improved gradually during the next 9 days, and her serum lipase became normal by hospital day 10 . She was gradually restarted on a low-fat, low-cholesterol diet, and lipid-lowering therapy (ie, gemfibrozil $600 \mathrm{mg}$ twice-a-day) was begun. The patient was discharged after 14 days of hospitalization. At the time of discharge, her serum triglyceride and cholesterol levels were $303 \mathrm{mg} / \mathrm{dL}$ and $202 \mathrm{mg} / \mathrm{dL}$, respectively. She was asymptomatic at 3 months' follow-up.

\section{Discussion}

Patients with acute pancreatitis typically complain of upper quadrant abdominal pain that radiates to the back, is relieved by sitting up, and is associated with nausea and vomiting. ${ }^{1}$ Some, however, can have nonspecific complaints and varied findings on physical examination. ${ }^{1}$ Clinicians must thus rely on such laboratory tests as serum amylase and lipase to support the diagnosis. Because the serum amylase assay tends to be less expensive and more read- 
ily available than lipase assay in most hospitals, most clinicians will obtain amylase measurements first in cases of suspected pancreatitis. ${ }^{1,2}$ Recognizing factors that reduce the sensitivity and specificity of serum amylase and lipase can help prevent unnecessary invasive diagnostic procedures and allow for appropriate treatment. One factor that can lead to spuriously normal amylase values is hypertriglyceridemia. ${ }^{3}$ Specific treatment to reduce serum triglycerides can hasten clinical recovery during the acute episode and allow risk factor modification. 4,5

Patients with acute pancreatitis and concomitant hypertriglyceridemia most commonly report a history of poorly controlled diabetes, alcoholism, predisposing pharmacologic agents (such as estrogens, diuretics, or glucocorticoids), ${ }^{2}$ or dietary risk factors. ${ }^{6}$ The incidence of hyperlipidemia in patients with acute pancreatitis has been reported in the range of 12 to 38 percent, ${ }^{7}$ which encompasses patients with transient, mild lipid abnormalities that would not precipitate acute pancreatitis. Our report, however, refers specifically to the 4 to 19 percent of patients with acute pancreatitis who have elevated concentrations of particulate triglycerides in their plasma. ${ }^{7,8}$ In this subset of patients, hypertriglyceridemia can act as both a precipitating cause and a continuing risk factor for pancreatitis. ${ }^{5}$

Hypertriglyceridemia compounds the diagnosis of acute pancreatitis by causing spuriously normal amylase levels. ${ }^{3}$ Plasma triglyceride levels higher than $500 \mathrm{mg} / \mathrm{dL}$ interfere with in vitro determination of the actual amylase level by preventing the calorimetric reading of the assay end point. ${ }^{2}$ Serial dilutions of the patient's sample with the assay buffer to reduce interference of light transmission by hyperlipidemic serum can reveal an abnormal amylase value that was previously masked by the lactescent plasma. ${ }^{3}$ Other studies investigating the potential role of circulating amylase inhibitors have not been well substantiated. ${ }^{9,10}$ Alternatively, patients with hypertriglyceridemia can also have a more insidious course of disease progression than other patients with acute pancreatitis, resulting in normalization of amylase levels by the time they seek medical help. ${ }^{8}$

Determining the sensitivity and specificity of serum amylase and lipase assays is difficult because of (1) the lack of randomized, controlled studies involving patients with confirmed diagnosis of pancreatitis, (2) the failure to document the timing of enzyme elevations relative to the course of the disease in most studies, and (3) the lack of standardized enzyme detection methods. ${ }^{2}$ The sensitivity and specificity of amylase and lipase are reported to vary considerably depending on the detection method used, ranging from 70 to 100 percent and 33 to 89 percent for serum amylase, and from 74 to 100 percent and 34 to 100 percent for serum lipase, respectively. ${ }^{2}$ Within these ranges, most recent studies document higher sensitivity and specificity for lipase. ${ }^{1,2}$ Because elevated serum lipase is not masked by hypertriglyceridemia, lipase may be used to improve diagnostic sensitivity in cases of suspected pancreatitis with normal amylase values. Clavien et $\mathrm{a}^{8}$ have shown that the overall diagnostic sensitivity for acute pancreatitis improved from 81 to 94 percent when serum lipase was measured in addition to amylase. As illustrated by this case report as well, serum lipase levels should be obtained in patients suspected to have acute pancreatitis despite normal amylase levels.

Treatment of acute pancreatitis generally includes intravenous fluid replacement, pain management, restoration of fluid and electrolyte balance, and observation either in the intensive care unit or on the medical unit depending on initial clinical assessment. " Patients who fail to improve within 72 hours or who deteriorate rapidly require dynamic contrast CT to rule out necrotizing pancreatitis. " Symptomatic patients with necrotizing pancreatitis should undergo CT-guided fine-needle aspiration to rule out infection and to determine whether surgical intervention is required.1,11

Overall, although pancreatitis caused by hypertriglyceridemia has the same prognosis as other causes of the acute episode, ${ }^{6}$ early recognition and treatment have been shown to hasten clinical recovery. ${ }^{5,12}$ In addition to insulin, which promotes tissue uptake of lipids, specific treatment modalities can include fresh frozen plasma ${ }^{13}$ and plasmapheresis. ${ }^{5,12}$ Plasmapheresis has been shown to cause dramatic clinical improvement in patients with acute pancreatitis and to prevent disease recurrences. ${ }^{5}$ The benefits of these treatments might relate to the elimination of excessive plasma proteases associated with acute pancreatitis, either by direct removal by plasmapheresis ${ }^{12}$ or replenishment of protease inhibitors, such as alpha ${ }_{2}$-macroglobulin, by donor plasma. ${ }^{13}$ In the recovery phase, treatment should also include elimination of secondary causes of hypertriglyceridemia, dietary 
modification with pharmacologic reduction of triglycerides, if necessary, and avoidance of alcohol consumption. ${ }^{14}$

In summary, hypertriglyceridemia can lead to the erroneous exclusion of acute pancreatitis as a diagnostic possibility because hypertriglyceridemia can cause spuriously normal amylase levels. Recognizing this subset of patients with acute pancreatitis can lead to more efficacious acute treatment and long-term risk factor modification.

\section{References}

1. Ranson JH. Diagnostic standards for acute pancreatitis. World J Surg 1997;21:136-42.

2. Wong EC, Butch AW, Rosenblum JL. The clinical chemistry laboratory and acute pancreatitis. Clin Chem 1993;39:234-43.

3. Fallat RW, Vester JW, Glueck CJ. Suppression of amylase activity by hypertriglyceridemia. JAMA 1973;225:1331-4.

4. Chait A, Brunzell JD. Chylomicronemia syndrome. Adv Intern Med 1992;37:249-73.

5. Piolot A, Nadler F, Cavallero E, Coquard JL, Jacotot $B$. Prevention of recurrent acute pancreatitis in patients with severe hypertriglyceridemia: value of regular plasmapheresis. Pancreas 1996;13:96-9.

6. Fortson MR, Freedman SN, Webster PD 3rd. Clin- ical assessment of hyperlipidemic pancreatitis. Am J Gastroenterol 1995;90:2134-9.

7. Brunzell JD, Schrott HG. The interaction of familial and secondary causes of hypertriglyceridemia: role in pancreatitis. Trans Assoc Am Physicians 1973;86:245-54.

8. Clavien PA, Robert J, Meyer P, Borst F, Hauser H, Herrmann F, et al. Acute pancreatitis and normoamylasemia. Not an uncommon combination. Ann Surg 1989;210:614-20.

9. Mishkin S, Bates J, O'Hashi J, Schneider P, Sniderman AD, Wolf RO. Possible mechanisms of normal amylase activity in hyperlipemic pancreatitis. Can Med Assoc J 1976;115:1016-9.

10. Kessler JI, Miller M, Barza D, Mishkin S. Hyperlipemia in acute pancreatitis. Metabolic studies in a patient and demonstration of abnormal lipoproteintriglyceride complexes resistant to the action of lipoprotein lipase. Am J Med 1967;42:968-76.

11. Tènner S, Banks PA. Acute pancreatitis: nonsurgical management. World J Surg 1997;21:143-8.

12. Larvin $M$, Lansdown MR, McMahon MJ, Chalmers AG, Turney JH, Brown AM. Plasmapheresis: a rational treatment for fulminant acute pancreatitis? BMJ 1988;297:593-4.

13. Leese T, Holliday M, Heath D, Hall AW, Bell PR. Multicenter clinical trial of low volume fresh frozen plasma therapy in acute pancreatitis. Br J Surg 1987;74:907-11. 